\title{
The ecological significance of time sense in animals
}

\author{
Leslie Ng ${ }^{1,2, *}$, Jair E. Garcia ${ }^{2}$, Adrian G. Dyer ${ }^{2,3, \dagger}$ and Devi Stuart-Fox ${ }^{1, \dagger}$
}

${ }^{1}$ School of BioSciences, The University of Melbourne, Parkville, VIC 3010, Australia

${ }^{2}$ Bio-Inspired Digital Sensing (BIDS) Lab, School of Media and Communication, RMIT

University, Melbourne, VIC 3001, Australia

${ }^{3}$ Department of Physiology, Monash University, Melbourne, Clayton, VIC 3800, Australia

Page heading: Ecological significance of time sense in animals

*Author for correspondence (E-mail: tszn1@student.unimelb.edu.au; Tel.: +61 41876 0331).

${ }^{\dagger}$ Authors contributed equally.

\begin{abstract}
Time is a fundamental dimension of all biological events and it is often assumed that animals have the capacity to track the duration of experienced events (known as interval timing). Animals can potentially use temporal information as a cue during foraging, communication, predator avoidance, or navigation. Interval timing has been traditionally investigated in controlled laboratory conditions but its ecological relevance in natural environments remains unclear. While animals may time events in artificial and highly controlled conditions, they
\end{abstract}

This is the author manuscript accepted for publication and has undergone full peer review but has not been through the copyediting, typesetting, pagination and proofreading process, which may lead to differences between this version and the Version of Record. Please cite this article as doi: $10.1111 /$ brv.12665

This article is protected by copyright. All rights reserved. 
may not necessarily use temporal information in natural environments where they have access to other cues that may have more relevance than temporal information. Herein we critically evaluate the ecological contexts where interval timing has been suggested to provide adaptive value for animals. We further discuss attributes of interval timing that are rarely considered in controlled laboratory studies. Finally, we encourage consideration of ecological relevance when designing future interval-timing studies and propose future directions for such experiments.

Key words: animals, communication, ecological, foraging, interval timing, navigation, predator avoidance, temporal information, time perception.

\section{CONTENTS}

I. Introduction

II. The study of interval timing in animals

III. Mechanisms of interval timing

IV. Foraging

(1) Optimality in foraging

(2) Speed-accuracy trade-offs

(3) Timing food-replenishment intervals

(4) Time-place learning

V. Communication

(1) The role of interval timing in communication

This article is protected by copyright. All rights reserved. 
(2) Timing of temporal elements and patterns

VI. Predator avoidance

(1) Timing predator exposure

(2) Refuge-hiding behaviour

VII. Navigation

VIII. Interval timing outside the laboratory

IX. Future directions

X. Conclusions

XI. Acknowledgements

XII. References

\section{INTRODUCTION}

Time is a fundamental dimension in how we experience the world around us; we have the capacity to perceive the duration of events subjectively, and use this information in our decision-making (Fontes et al., 2016). The same is true for some animals that may use temporal information as cues in foraging, communication, predator avoidance or navigation. There is increasing evidence from laboratory studies that some animals can learn tasks requiring timing of events; but how such findings translate to biologically relevant tasks is often unclear. Currently there exists no detailed synthesis of evidence regarding the adaptive value of time sense in animals. The purpose of this review is to evaluate critically the adaptive value of time sense, to discuss the strength of this evidence in relation to different 
ecological contexts, and to provide a framework for future investigations of how different animals may show evidence of time sense.

Time perception entails a representation in the brain based on available sensory information. This representation is peculiar as it does not directly map to a tangible stimulus, and is not associated with a specialised organ (Wittmann \& Van Wassenhove, 2009). Nevertheless, time perception has similarities with other sensory perceptions; for example, duration judgements follow Weber’s law (Grondin, 2001), are influenced by factors such as motivation (Gable \& Poole, 2012), and can be integrated with other senses such as spatial information to form multimodal representations (e.g. episodic memory formation; Copara et al., 2014; Eichenbaum, 2017). Time perception involves different mechanisms depending on the scale at which an event is timed. Studies of time perception in animals often focus on tracking temporal regularities that occur in large (in the range of hours) or predictable cycles (Vasconcelos, de Carvalho \& Machado, 2017). The timings of these events have been attributed to circadian timing mechanisms where animals may store a specific time of day in memory to optimise foraging or predator avoidance (Mulder, Gerkema \& Van der Zee, 2013). Alternatively, timing of events can also occur at relatively short scales of seconds to minutes. Timing of these events is attributed to an interval-timing mechanism, where it is often suggested that a clock-like mechanism is tracking the onset and end of events (Wilkie et al., 1994; Bateson, 2003; Vasconcelos et al., 2017). Circadian timing mechanisms have been studied extensively and are relatively well understood (Hardin, 2005; Toh, 2008; Mulder et al., 2013). Here, we focus on interval timing at short timescales. 
Herein, we discuss the ecological contexts in which interval timing has been suggested to be used by animals, namely, foraging, communication, predator avoidance, and navigation (Table 1). We discuss aspects of interval timing in ecological contexts that are rarely considered in laboratory experiments, and the importance of different sources of evidence for interval timing. Much of the literature has assumed that animals can use temporal information during decision-making, but direct evidence for this in ecologically relevant conditions is rare. Furthermore, the specific neural mechanisms behind interval timing in different animals remain largely unclear. Investigating the use of interval timing under ecologically relevant conditions requires a creative and informed approach towards experimental design that considers the biology of the animal, and information that it has access to in its natural environment. We propose future directions for behavioural experiments that will provide an insight into the ecological relevance of interval timing.

\section{THE STUDY OF INTERVAL TIMING IN ANIMALS}

Interval timing in animals has been traditionally investigated using experimental procedures such as peak procedure, temporal bisection, temporal generalisation, or fixed interval schedules [see MacInnis \& Guilhardi (2006) and Vasconcelos et al. (2017) for reviews] . These procedures are conducted in controlled laboratory environments where an animal is generally trained to learn specific time schedules. Such experiments provide evidence for interval-timing capacity in some animals (fixed interval studies summarised in Craig \& Abramson, 2015) such as mammals (e.g. Church \& Gibbon, 1982; Craig et al., 2015;

Heinrich, Dehnhardt \& Hanke, 2016), birds (Brodbeck, Hampton \& Cheng, 1998; Ohyama et 
al., 1999; Penney, Gibbon \& Meck, 2008), some fish (Higa \& Simm, 2004; Drew et al., 2005), and an insect (Boisvert \& Sherry, 2006). These studies demonstrate that some animals can anticipate and respond to temporally repeating food schedules (fixed interval), store and reproduce intervals from memory (peak procedure), compare and discriminate different intervals (temporal generalisation), and categorise intermediate durations as either short or long (bisection task). Notably, there can be large differences in interval-timing performance between closely related species, such as honeybees (Apis mellifera) and bumblebees (Bombus impatiens; Boisvert \& Sherry, 2006; Craig et al., 2014), or pigeons (Columba livia) and turtle doves (Streptopelia risoria; Lejeune \& Richelle, 1982). Therefore, generalisations about time sense in animals based on studies of limited model species need to be considered cautiously. Evidence for interval timing can be found in neural, psychophysics, and behavioural ecology studies. Neural evidence for interval timing demonstrates the fundamental capacity of animals to process temporal information during different tasks. For example, Paulk et al. (2008) showed that neurons in the bumblebee visual system can code temporal properties of signals. Alternatively, psychophysics experiments are important in determining properties of relevant neural mechanisms, such as the observation of scalar properties (i.e. standard deviation of time estimates increases linearly with interval duration) in humans and other animals (Gibbon, 1977), or the influence of different parameters on timing mechanisms such as attention or interval length (Church, Getty \& Lerner, 1976; Boisvert \& Sherry, 2006; McMillan et al., 2017). Together, neural and psychophysics studies provide evidence that intervals can be timed and identify parameters that affect timing performance, but not how time sense is used in natural contexts. Behavioural ecology studies, which consider the 
biology of the focal species, are also necessary to understand the biological and ecological significance of interval timing. Consequently, a combination of all three sources of evidence is required to gain a comprehensive understanding of interval timing in animals (Fig. 1). Interval timing has also been suggested to play an important role in associative learning (Balsam, Drew \& Gallistel, 2010). When forming associations between stimuli, it appears that animals process the temporal relations between events (Balsam \& Gallistel, 2009). This implies that all animals capable of associative learning have some capacity to process time. However, if this is the case, why do animals such as honey bees that have well-developed associative learning capacities (Giurfa, 2007) fail in interval-timing experiments (Grossmann, 1973; Craig et al., 2014)? The likely answer is that animals do not necessarily use time as a cue even if they have the capacity to do so, especially in complex natural environments. Therefore, ecologically relevant experiments are essential to understand the importance of time sense in non-human animals.

\section{MECHANISMS OF INTERVAL TIMING}

The mechanisms responsible for interval timing have been extensively discussed and various frameworks have been proposed to explain how animals process temporal information [reviewed in Matell \& Meck (2000) and Paton \& Buonomano (2018)]. Currently, the most influential frameworks are pacemaker-accumulator clock models such as the scalar expectancy theory (SET; Gibbon, 1977). Here, a pacemaker controlled by a switch produces pulses that are accumulated and stored in memory. The pulses are then summed and compared with a reference memory to determine if the intervals match. SET has become a 
standard model of timing in the animal literature and consequently time sense in animals is often discussed in terms of a clock-like mechanism (Brunner, Kacelnik \& Gibbon, 1992; Bateson, 2003; Kleinman, Sohn \& Lee, 2016; Vasconcelos et al., 2017). Interval timing has also been modelled using oscillator models such as the striatal beat-frequency model (SBF) or dynamic attending theory (DAT), where oscillatory neural patterns generate a unique time code or adapt to an existing temporal pattern (Jones \& Boltz, 1989; Matell \& Meck, 2004). Alternatively, behavioural models such as the behavioural theory of timing (BET) or learning-to-time (LET) suggest that animals can time intervals using a series of behavioural states without the need for complex cognitive mechanisms (Killeen \& Fetterman, 1988; Machado, 1997). For example, in BET, an animal transitions between behavioural states (e.g. a pigeon transitioning from head-bobbing at one location, to pecking at another location) driven by an internal pacemaker, and the behavioural state coinciding with the reinforcer will be conditioned to elicit a response. However, current consensus in the human literature is converging towards decentralised clock models where timing is thought to be an emergent property of neural dynamics (Buonomano \& Laje, 2011; Goel \& Buonomano, 2014; Paton \& Buonomano, 2018). For example, population clock models suggest that timing is encoded in changing neural population dynamics after the onset of a stimulus, and the trajectory and pattern of these dynamics can act as a unique time code for a time interval (Jin, Fujii \& Graybiel, 2009; Buonomano \& Laje, 2011). Ultimately, temporal processing is highly complex and is involved in a variety of tasks and brain regions (Grondin, 2010; Paton \& Buonomano, 2018); therefore, a range of mechanisms are likely necessary to process temporal cues for different tasks. 
To date, most studies investigating such mechanisms are centred around humans and select model species such as rats (Buhusi \& Meck, 2002; Matell, Meck \& Nicolelis, 2003; Xu et al., 2014), but whether other animals share the same timing mechanisms remains an open question. It is also unclear whether an animal's neural representation of time intervals is linear or logarithmic (Kim et al., 2013), although increasing evidence suggests that animals represent time logarithmically (Roberts, 2006; Kim et al., 2013; Sarpeshkar, 2014). This could be adaptive for the efficient processing of long durations, which may require a large working memory if timing is linear (Y. Ren, H. Müller \& Z. Shi, in preparation). Further, different animals may process time in different ways depending on their ecology.

Understanding the importance of time sense under various ecological contexts may therefore provide insights into the neural mechanisms required to process temporal information in natural environments.

\section{FORAGING}

Interval timing is frequently assumed to play an integral role in foraging (Brunner et al., 1992; Boisvert, Veal \& Sherry, 2007; Heinrich et al., 2016). Foraging takes time, and food resources can vary in terms of profitability and acquisition rate. Therefore, efficient time expenditure during foraging activities is thought to be under strong selection (Bateson, 2003).

\section{(1) Optimality in foraging}

How animals efficiently collect food resources has largely been discussed in the context of optimal foraging theory (Stephens \& Krebs, 1986). In general, these models predict that 
natural selection acts to maximise some fitness currency such as energy gain or efficiency (Brunner et al., 1992; Bateson, 2003; Hazen, Friedlaender \& Goldbogen, 2015). This implicitly assumes that animals can measure the rate of resource acquisition and that this directly influences their decision-making. For example, ants (Camponotus rufipes), honeybees (Apis mellifera), and wasps (Paravespula germanica) appear to be sensitive to nectar flow rates when foraging from artificial feeders, and modify their foraging behaviours accordingly (Pflumm, 1986; Wainselboim, Roces \& Farina, 2002; Schilman \& Roces, 2003). Rats have also been shown to measure the time required to consume a piece of food, and directly use this information when engaging in food protection behaviours (Whishaw \& Gorny, 1994; Wallace et al., 2006).

By assessing a proxy for energy gain (e.g. food consumed) over time, animals can determine whether to continue foraging at a patch, or to move to another patch once food is depleted. This is often modelled using patch-departure models such as the marginal value theorem (MVT) or Bayesian update models which describe how an animal should behave in such situations (Charnov, 1976; Green, 1984; Bateson, 2003; Marshall et al., 2013). For example, the MVT suggests that an animal will opt to leave a patch once its foraging rate drops to the average food gain rate across all patches in the habitat (Nonacs, 2001). Most optimal patchdeparture models assume that temporal information is important when considering when to leave the patch, but do not explain the proximate mechanisms required to make such calculations (Kacelnik, Brunner \& Gibbon, 1990). An exception to this is the collection of work applying SET to MVT (Kacelnik et al., 1990; Kacelnik \& Brunner, 2002). These works demonstrate that animals can anticipate the expected timing of a reward and make decisions 
to leave the patch based on this anticipated time. Scalar properties can be observed in the time at which an animal moves to another patch and the time of the last foraging response in a patch, demonstrating that animals can adjust the waiting time at a patch based on the food schedules experienced (Brunner et al., 1992; Kacelnik \& Brunner, 2002; Bateson, 2003). Variability in the amount of food or the time it takes to find food is also assumed to play a role in foraging decisions (Bateson, 2003; Kacelnik \& El Mouden, 2013; Craft, 2016). For example, animals may decide to forage at a patch where search time is fixed, or another patch where search time is more variable. Risk-sensitive foraging theory suggests that animals may adopt either a risk-prone or risk-averse strategy depending on the foraging context, energy budget, or search time variability (Caraco, Martindale \& Whittam, 1980; Kacelnik \& El Mouden, 2013; Craft, 2016). This implies that animals can assess variation in search time for each patch, and develop preferences towards fixed or variable foraging options (Caraco et al., 1980; Bateson \& Kacelnik, 1995; Bacon, Hurly \& Healy, 2010; Craft, 2016). However, whether animals use interval timing to assess search time variability remains unclear. Optimal foraging is an attractive framework for evaluating time sense, but it is often difficult to test modelled predictions in natural systems. The extent to which interval timing contributes to foraging optimality in general has received limited attention, especially in relation to cognitive mechanisms other than SET. Furthermore, animals may use other physiological cues to measure rate of resource acquisition, foraging duration, search time, and other time-related currencies. This can result in behaviours that appear to involve time sense but in fact do not. For example, animals that forage underwater may resurface based on depleting oxygen levels rather than specifically tracking dive duration (Ponganis, Meir \& 
Williams, 2010). The distinction between physiological mechanisms or constraints and time sense is important as interval timing is an active process that requires the animal to make decisions based on temporal mechanisms.

\section{(2) Speed-accuracy trade-offs}

When managing time expenditure during foraging tasks, there may be a trade-off between speed and accuracy. Speed-accuracy trade-offs are well-studied in humans, where individuals can either make quick decisions with low accuracy or slow decisions with high accuracy (Pachella \& Fisher, 1969; Bogacz et al., 2010; Heitz, 2014; Drugowitsch et al., 2015). In animals, speed-accuracy decisions are often consistent within individuals but some flexibility also exists (Rinberg, Koulakov \& Gelperin, 2006; Chittka, Skorupski \& Raine, 2009; Heitz \& Schall, 2012; Wang, Chittka \& Ings, 2018). For example, bumblebees (Bombus terrestris) switch to a slower but more accurate strategy in a colour-discrimination task when incorrect choices are punished, or when the task is more difficult (Chittka et al., 2003; Dyer \& Chittka, 2004). Bumblebees also slow their inspection flights when under risk from cryptic predators, indicating that speed-accuracy trade-offs occur in ecologically relevant situations (Ings \& Chittka, 2008). The ability of individuals to adjust speed-accuracy decisions to improve foraging efficiency has often been suggested to imply a sensitivity to time intervals. However, responses to food rewards or other cues may result in differences in foraging behaviour consistent with speed-accuracy trade-offs. This is because any type of response towards stimuli costs time, but such behaviours may not directly require a sense of time. 


\section{(3) Timing food-replenishment intervals}

Some sources of food replenish at predictable intervals and animals can track the time they last foraged at a resource to improve foraging efficiency. Many animals have the ability to track food schedules as evidenced by fixed-interval studies (Fig. 2; Craig \& Abramson, 2015), but this type of behaviour may only be ecologically relevant for animals that exploit rapidly replenishing food sources, such as pollinators that forage from flowers that replenish throughout the day (Henderson et al., 2006; Boisvert et al., 2007; Toelch \& Winter, 2013). This is reflected in the traplining behaviour of some pollinators, where animals visit food sources in spatially repeatable patterns (Boisvert et al., 2007; Lihoreau et al., 2013; TelloRamos, Hurly \& Healy, 2015). Such visitation patterns are thought to be based on the replenishment schedule of flowers and indeed studies have shown that pollinators can track replenishing food schedules. Henderson et al. (2006) demonstrated that rufous hummingbirds (Selasphorus rufus) can distinguish between artificial flowers with schedules of 10 or 20 minutes and can remember and avoid flowers they recently visited. Similarly, Boisvert et al. (2007) showed that bumblebees (Bombus impatiens) could remember when a high-quality reward was available at a feeder at different fixed-interval schedules and time their visitations accordingly (Fig. 3). In nature, it may take considerably longer for flowers to replenish compared to the schedules presented in these studies (Tello-Ramos et al., 2015); however, flowers exhibit increased nectar production in response to nectar draining and some species rapidly replenish at schedules of under an hour (Thomson, McKenna \& Cruzan, 1989; Castellanos, Wilson \& Thomson, 2002; Luo, Ogilvie \& Thompson, 2014). Therefore, it is 
plausible that flowers replenish at a scale that is reliably tracked by interval-timing mechanisms.

\section{(4) Time-place learning}

Where and when a foraging event occurs can be useful for animals to learn, as they can change foraging sites according to spatiotemporal schedules of their food source (Thorpe \& Wilkie, 2006a; Vasconcelos et al., 2017). This is similar to tracking food replenishment intervals, but there is greater emphasis on the relationship between time and location of one or many foraging sites, rather than simply tracking the time last foraged at a specific resource. Most studies investigating time-place learning (TPL) make use of mazes where animals can find food in different arms, levers, or compartments depending on the time of day (Biebach, Gordijn \& Krebs, 1989; Carr \& Wilkie, 1997; Moura \& Luchiari, 2016). The mechanisms at this timescale likely involve circadian timers where animals are associating the food location with time of day (Saksida \& Wilkie, 1994), or an ordinal timer where animals are associating food location according to its order in a temporal pattern (Carr \& Wilkie, 1997). However, TPL can also be facilitated by interval-timing mechanisms (Thorpe \& Wilkie, 2006a). Rats and pigeons have the capacity to learn both spatial and temporal contingencies in TPL tasks at short timescales of minutes (Pizzo \& Crystal, 2004; Thorpe \& Wilkie, 2006b; García-Gallardo \& Carpio, 2016). The majority of TPL studies are performed in controlled laboratory conditions and therefore the ecological relevance of TPL at intervaltiming scales remains unclear.

This article is protected by copyright. All rights reserved. 
An extension to TPL are studies investigating what, where, when (WWW) memories in the context of episodic memory in animals. Here, animals need to learn and remember the spatiotemporal characteristics of a food source in addition to the identity of the food item itself. This is especially relevant for food-storing animals that cache perishable foods and need to remember the time and type of food item stored to predict how much it may have degraded over time (Clayton \& Dickinson, 1998, 1999; Feeney, Roberts \& Sherry, 2009; Zinkivskay, Nazir \& Smulders, 2009). However, such studies usually involve large timescales of several hours as food items do not often perish at interval-timing scales. MartinOrdas et al. (2010) provide a unique example where bonobos (Pan paniscus), chimpanzees (Pan troglodytes) and orangutans (Pongo pygmaeus) had to choose either frozen juice (preferred) or a grape (less preferred) after intervals of either 5 min or $1 \mathrm{~h}$. The animals preferred frozen juice after 5 min intervals but preferred the non-perishable grape after $1 \mathrm{~h}$. WWW tasks can also occur in the context of replenishing resources as different food resources may renew at different rates depending on the food type. For example, Salwiczek \& Bshary (2011) presented free-swimming cleaner wrasse (Labroides dimidiatus) with differently coloured and patterned plates that were associated with different time intervals, such that the fish were only allowed to feed off the plate after the corresponding time interval had passed. This time interval was biologically relevant as each plate simulated a client fish, and these clients are regularly reinfected with ectoparasites (Salwiczek \& Bshary, 2011). Cleaner wrasse were able to remember when and which plate they had previously interacted with to complete an optimal foraging task. In the same way, short timescales are biologically 
relevant for pollinators that can benefit from time-place or WWW information as they can travel to different patches in a sequence according to patch-specific temporal schedules.

\section{COMMUNICATION}

\section{(1) The role of interval timing in communication}

Animal communication is often suggested to involve interval timing (MacDonald \& Meck, 2003; Vasconcelos et al., 2017; Motanis, Seay \& Buonomano, 2018). However, the role of interval timing is difficult to evaluate in the context of communication due to the complexity of such signals. Many communication signals occur in the range of seconds to minutes, but are also often composed of temporal elements or patterns in the scale of milliseconds to seconds. To detect and process temporal signals at this resolution usually requires dedicated sensory mechanisms such as duration-selective neurons (Carlson, 2009; Elliott, ChristensenDalsgaard \& Kelley, 2011; Paton \& Buonomano, 2018). For example, thoracic auditory interneurons in acridid grasshoppers (Chorthippus biguttulus) selectively respond to $2 \mathrm{~ms}$ song gaps (Ronacher \& Stumpner, 1988). Therefore, neural mechanisms that process temporal communication signals can be very different to those involved in traditional interval-timing tasks depending on the timescale. Although the processing of signals in the

milliseconds (sub-second) versus seconds (supra-second) range appears to involve different neural circuits (Rammsayer, 1999; Karmarkar \& Buonomano, 2007; Rammsayer, Borter \& Troche, 2015), the temporal boundaries between the two are unclear. Consequently, the processing of temporally complex communication signals likely requires both active and 
cognitively mediated mechanisms that are associated with interval timing, and passive sensory mechanisms that detect sub-second information.

In addition, it can be tempting to conclude that highly specialised neural circuits such as those involved in communication are unrelated to interval timing in general. For example, the learning and production of bird songs are processed by a group of brain nuclei aligned with two connecting pathways: the posterior descending pathway (PDP), and the anterior forebrain pathway (AFP; Nottebohm, 2005; Mooney, 2009). The PDP is associated with the production and timing of a song, while the AFP is required for the learning of a song. These pathways are clearly specialised for the processing of temporal signals in bird songs and are likely unrelated to temporal processing in other contexts. However, it is possible that neural mechanisms for traditional interval-timing tasks are also highly specialised for each task or context, and therefore we cannot exclude communication signals from interval timing on this basis alone. Given the ambiguity of interval timing in communication signals, and the fact that the exact mechanisms of interval timing in general are unclear, we discuss the ecological relevance of timing in communication signals below but highlight that such signals are temporally complex and are known to involve specialised neural circuits.

\section{(2) TIMING OF TEMPORAL ELEMENTS AND PATTERNS}

When communicating with conspecifics, animals modulate the temporal patterns and structures of their communication signals (Pollack, 2000; Filippi et al., 2019; Ravignani et al., 2019). In some instances, the duration of the signal can provide meaningful information for the receiver. This is the case for honeybees that communicate information about a food 
source with their dance language (von Frisch, 1967). The duration of a component of the dance known as the waggle run is correlated with the distance of the food, and therefore followers must have the ability to time the waggle run (Seeley, Mikheyev \& Pagano, 2000). However, in most studied cases of signalling, it is the temporal pattern of individual elements within a signal that is important in communication. Advertisement calls in frogs (Wollerman \& Wiley, 2002; Tobias, Evans \& Kelley, 2011), flash patterns in fireflies (Lewis \& Cratsley, 2008), cricket stridulations (Zuk, Rebar \& Scott, 2008), fish acoustic signals (Kihslinger \& Klimley, 2002), and bird songs (MacDonald \& Meck, 2003; Dooling \& Prior, 2017), all contain species-specific temporal patterns that enable reliable signalling of species identity. Temporal patterns can also convey more specific information about individual identity. In cotton-top tamarins (Saguinus oedipus), individual identity, sex, and group identity can be encoded in their long calls (Weiss, Garibaldi \& Hauser, 2001). Temporal components of long calls appear to be particularly important in encoding sex and group identity. In African clawed frogs (Xenopus laevis), male-male encounter vocalisations are triggered by calls with a male-like temporal pattern; while both a female-like frequency and female-like temporal pattern are required to trigger courtship displays (Vignal \& Kelley, 2007). Additionally, temporal patterns can also provide information about individual quality that is used in mate preference or male-male competition, and acoustic performance has been correlated to male condition across multiple species (Scheuber, Jacot \& Brinkhof, 2003; Forsman \& Hagman, 2006; Richardson et al., 2010; Benítez et al., 2016). For example, the song rate or structure of male barn swallows (Hirundo rustica) is associated with male-quality traits such as body condition, testosterone level, parasite levels, or immunological condition in several studies 
(Møller, 1991; Galeotti et al., 1997; Saino et al., 1997). As acoustic displays are often energetically expensive, females can use temporal components of these signals as reliable predictors of mate and offspring quality (Scheuber et al., 2003; Forsman \& Hagman, 2006). While most studies discussed here relate to acoustic signals, temporal patterns exist in other modalities. Mormyrids (Brienomyrus brachyistius) communicate individual identity and behavioural state with patterns of electric discharges (Carlson \& Hopkins, 2004; Baker et al., 2013). Even colourful insect displays that interact with incident light have been suggested to be temporally dynamic signals (Schroeder et al., 2018). In general, many animals directly modulate temporal components in their signals regardless of modality, and specialised neural mechanisms responsible for the production or interpretation of such signals are often required to process these complex temporal components to inform decision-making (Nottebohm, 2005; Kostarakos \& Hedwig, 2014).

\section{PREDATOR AVOIDANCE}

Animals often find themselves in vulnerable situations during foraging or reproductive activities as these tasks may be associated with exposure to predation (Sih, 1992; Hedrick, 2000). Consequently, animals must manage how much time they spend engaged in risky behaviours (Lima \& Dill, 1990; Balaban-Feld et al., 2019). Interval-timing ability is therefore assumed to be important in determining the duration of predator exposure, particularly in light of trade-offs with foraging or other activities important for survival or reproduction. 


\section{(1) Timing predator exposure}

Many animals appear to assess threat level in a given situation and can adjust their behaviour accordingly (Houston, McNamara \& Hutchinson, 1993; Verdolin, 2006; Thaler, McArta \& Kaplan, 2012; Liesenjohann et al., 2015; Hefty \& Stewart, 2019). For example, black-capped chickadees (Parus atricapillus) achieve maximal efficiency when foraging directly next to a food source (Lima, 1985). However, in high-risk situations they opt to carry food items to cover, suggesting a capacity to manage feeding rate versus time exposed to predators. Similarly, air-breathing diving animals such as marine mammals or diving birds appear to manage how much time they spend at the surface where they are most vulnerable to predators (Dunphy-daly et al., 2010). Although these examples appear to show that animals can optimise their time allocation in response to predation risk, animals can also behave in these ways without the use of interval timing. For example, escape responses may be heightened in animals when they experience more predator encounters. In these circumstances, animals may be more likely to escape, hide, or avoid areas where predators have been located, and therefore will reduce predator exposure time without specifically relying on any intervaltiming mechanisms.

\section{(2) Refuge-hiding behaviour}

When avoiding predators, many animals make use of refuges into which they can retreat to hide (Jennions et al., 2003; Cooper, Hawlena \& Pérez-Mellado, 2010; Martín \& López, 2015). In this context, animals are assumed to be aware of how long they have spent in hiding to determine when they should emerge and resume normal behaviour. For example, fiddler 
crabs (Uca perplexa) modulate how long they spend hiding in their burrows depending on the proximity of the predator (Jennions et al., 2003). The decision when to emerge from a refuge can be complex as many animals are blind to information about the predator while they are hiding (Sih, 1992; Hugie, 2003; Martín \& López, 2015). If the animal emerges too early, they risk the chance that the predator has not yet left. However, waiting too long is also costly as this time could be spent foraging or finding a mate (Reaney, 2007; Rhoades \& Blumstein, 2007). This trade-off can be seen in the yellow-bellied marmot (Marmota flaviventris), where supplemental food placed next to their burrow resulted in the marmots emerging sooner from their burrows (Blumstein \& Pelletier, 2005). Therefore, the decision to emerge was influenced by energetic considerations and opportunity cost of remaining in the burrow. Animals may also consider the perceived risk of remaining in the refuge (Jennions et al., 2003), unique attributes of the refuge (Chavez-Solis \& Alcaraz, 2015), self-conspicuousness within the environment (Hedrick, 2000), behaviours of group members (Balaban-Feld et al., 2019), or mating opportunity costs (Reaney, 2007) when deciding time to emerge.

Refuge-hiding studies have often assumed that animals are primarily reliant on temporal information when making decisions on when to emerge. It is likely that an interval-timing mechanism is involved as animals are often unable to access other sources of information in their refuges. Even so, it is still possible that some animals are not tracking the absolute time but are relying on an unknown proxy. 


\section{NAVIGATION}

One well-studied navigation mechanism is path integration, where animals can track their position with respect to their starting position by integrating the direction and distance they have travelled (Mandal, 2018). A variety of potential odometer mechanisms have therefore been proposed to explain how animals determine distance travelled. This includes tracking energy expenditure (Heran \& Wanke, 1952), self-motion cues from proprioceptive and vestibular systems (Wohlgemuth, Ronacher \& Wehner, 2001; Wallace et al., 2002), optic flow (Esch et al., 2001), stride integration (Walls \& Layne, 2009; Wolf, Wittlinger \& Pfeffer, 2018), or the actual travel duration with a temporal odometer (Wolf, 2011). The temporal odometer theory is attractive as many animals are expected to have interval-timing ability and therefore have access to temporal information (Craig \& Abramson, 2015). For example, parasitoid Trichogramma wasps adjust their reproductive investment in a host based on the host egg size. They measure egg size with a temporal odometer by timing the travel duration from first contact with the egg, to contact with the substrate (Schmidt \& Smith, 1987; Parent, Brodeur \& Boivin, 2016). In this case, a temporal odometer is reliable as the distance is very short and the insect is likely moving at a relatively constant speed. However a temporal odometer is less reliable when travel time becomes more variable over larger distances, and this can be heavily influenced by factors such as differences in carrying a load during inbound or outbound journeys (Wolf, 2011). Despite its flaws, a temporal odometer cannot be ruled out as animals do not necessarily use the most optimal odometer mechanism. An internal cue such as time could be useful when navigating in conditions where external cues such as optic flow are unavailable (e.g. travelling in darkness; Chittka et al., 1999). Under 
changing conditions, it is not surprising that animals may use different or multiple odometers in each situation. This is seen in the desert ant (Cataglyphis fortis), which uses both stride integration and optic flow cues to determine distance travelled (Wolf et al., 2018). These two mechanisms interact dynamically to drive homing behaviour, allowing flexibility depending on the navigational context. In the same way, the temporal odometer may be used primarily in situations where it is most reliable, but otherwise integrated with other mechanisms to achieve optimal homing behaviour.

Although animals may have the capacity to track travel times, direct behavioural support for the temporal odometer remains scarce (Wolf, 2011). However, even in instances when an animal is not directly timing the distance travelled, some degree of interval timing may still be involved. For example, when measuring self-motion, animals need to integrate their movements with time to estimate distance (Aharon, Sadot \& Yovel, 2017). From this perspective, time sense is necessary when processing cues that exist as a rate, regardless of the specific odometer mechanism.

\section{INTERVAL TIMING OUTSIDE THE LABORATORY}

Interval-timing studies performed in laboratory conditions demonstrate the capacity of animals to time events, but these controlled environments sacrifice some understanding of how timing is used in ecological contexts outside the laboratory. For instance, in fixedinterval experiments, timing the food schedule is the only way reliably to improve foraging efficiency (Fig. 2). However, animals have access to a multitude of signals in natural environments and may not actively rely on timing in ordinary circumstances. Stimuli 
occurring in these natural environments are often multimodal and animals can process these signals in a variety of ways. Animals may opt to ignore unreliable temporal information and instead process other components of the signal when making decisions. Indeed, interval timing is highly context dependent in humans and can be an inaccurate information source (Sackett et al., 2010; Lake, LaBar \& Meck, 2016). Consequently, alternative cues may be more reliable and act as proxies for interval duration. For example, animals do not often measure absolute distance but can use odometer mechanisms such as stride integration to determine distance travelled (Wolf, 2011). In a similar way, animals can use low-level cues to solve time-related tasks without the capacity to measure time intervals directly. Even if animals do use temporal information in their daily lives, the way in which they do so may be very different to how timing problems are presented in laboratory conditions. While timing studies often require an animal to track a precise start and stop time, the onset of a stimulus to be timed is likely to be more ambiguous in natural settings (van Rijn, 2018). Food is not always available at clearly defined and repetitive time schedules in nature, and proficiency in timing such tasks may not be informative for how animals use time in real foraging decisions.

Factors unrelated to timing capacity can also have a significant effect on timing performance but are underappreciated in the animal timing literature. For example, attentional mechanisms play an important role in timing (Brown \& West, 1990; Brown, 2008; Grondin, 2010). In humans, attention has clear effects on interval-timing performance, so it is not surprising that animals may be similarly affected (Sackett et al., 2010). While attention is often maximised in controlled laboratory conditions, animals in natural environments are often attending to 
multiple sources of information at once. In addition, animals that rely on their time sense are also likely tracking multiple time schedules concurrently. This has been explored in some studies, with evidence for the capacity to track multiple time schedules concurrently in rhesus monkeys (Macaca mulatta) and even bumblebees (Boisvert \& Sherry, 2006; Kleinman et al., 2016). However, the extent to which attention affects timing performance and how animals manage multiple sources of temporal information in a noisy natural environment are unclear. The ecological context of timing tasks can also influence behavioural strategies, and therefore timing performance. For example, food-deprived pigeons have difficulty timing stimuli of increasingly longer duration than a reference duration, while pigeons under no deprivation discriminated long durations better than short durations (Zeiler, 1991). This suggests that the way that animals use temporal information may be context dependent. The use of temporal information itself may also be a strategy that is only used under specific circumstances. Animal timing studies are often constrained to enable precision and as such they explore only one timing context, but animals that have time sense may not necessarily use time in every context.

Finally, while the capacity for animals to experience emotion remains a debated topic (de Vere \& Kuczaj, 2016; Paul \& Mendl, 2018), emotional states affect interval timing in humans (Yamada \& Kawabe, 2011; Lake et al., 2016). Specifically, high arousal states (often in response to negative or aversive stimuli) can make timed durations be perceived as longer (Langer, Wapner \& Werner, 1961; Tipples, 2008; Yamada \& Kawabe, 2011). If animals experience emotional states to some degree, their time sense may be influenced by arousal in similar ways. In natural situations, animals can experience high arousal in response to 
predator encounters, which may influence how they time behaviours such as refuge hiding. Emotional state is not generally controlled for in animal timing studies and its effect on timing performance remains unknown.

\section{FUTURE DIRECTIONS}

To gain a complete understanding of interval timing in ecological contexts, it is vital to consider the biology and ecology of the species of interest. We provide a framework for the design of ecologically informed interval-timing experiments in Fig. 4. Below we outline five research recommendations to evaluate the ecological relevance of interval timing.

(1) Do animals that use interval timing in laboratory conditions also do so in natural conditions? While there is evidence for interval timing in laboratory conditions (Craig \& Abramson, 2015), it is significantly more challenging to test this in ecological settings where animals may be relying on cues other than time. In some cases, it may be possible to control for cues other than temporal information. For example, studies investigating path integration in invertebrates often control for multiple cues to rule out the possibility of a temporal odometer (Wohlgemuth et al., 2001; Walls \& Layne, 2009). However, it is not always logistically possible to control for every cue that may be correlated with time. In this case, one approach involves testing if animals can flexibly use time cues of their own volition. For example, in a study by Boisvert et al. (2007), bumblebees were able to forage from a patch of low-quality feeders with a high-quality feeder that only provided reward after a fixed delay (Fig. 3). Here, bumblebees timed their visits to the high-quality feeder, showing that they could voluntarily use temporal cues to increase their foraging efficiency. Another example is 
the mid-session reversal task where an animal is trained simultaneously to discriminate and respond to two stimuli (Cook \& Rosen, 2010; Rayburn-Reeves, Molet \& Zentall, 2011). One stimulus is reinforced for the first half of the trial while the other stimulus is reinforced during the second half. The type of cue used to solve this task can be deduced by examining when the animal switches between responses and the types of errors made. While pigeons consistently appear to use passage of time to predict the mid-session reversal (Zentall, 2020), rats will often use their spatial orientation between each response as a cue if not controlled for (McMillan, Kirk \& Roberts, 2014). Therefore, the conditions of the task clearly affect the type of cue that is used to solve it. Overall, these types of experimental design can demonstrate whether animals flexibly use time sense to solve foraging problems and the conditions in which they do so.

(2) What influences interval timing in ecological settings, and to what extent? Studies of timing in humans have shown that interval timing is complicated and influenced by factors such as attention or arousal. This can result in interval timing being less accurate or reliable in complex environments. Investigating such factors may also provide insight into the underlying timing mechanism of the animal, as well as the interval-timing model most consistent with performance. For example, not all models consider the effect of attention and cognitive load on time perception (Block, Hancock \& Zakay, 2010; Addyman, French \& Thomas, 2016). In general, it is likely that timing in animals is similarly complex to timing in humans, but internal and external factors that influence timing have rarely been considered in animal studies. 
(3) How does interval timing vary among contexts? Interval timing may be specialised to specific tasks but may not be reliable in other contexts. Animals are generally only tested in a single experimental paradigm when testing for interval-timing capacity, therefore it is unclear how timing varies across different contexts, or whether animals that show no evidence of time sense in one context do so in another.

(4) Does interval-timing capacity differ among species, and if so, why? Interval timing is potentially adaptive in contexts such as foraging, communication, reproduction, navigation, and predator avoidance (Table 1). As these are activities relevant for the survival of every animal, it brings into question why individuals or species may differ in interval-timing capacity. Whether these differences reflect variations in lifestyle or cognitive strategies is unknown.

(5) What is the interval-timing capacity of understudied species? While mammals and birds are relatively well represented in the interval-timing literature, the timing capacity of many other species remains unknown, especially amongst reptiles and invertebrates. Testing such species using neurobiological or traditional psychophysics approaches is important to understand the evolution of interval timing in animals, allowing us then to explore how these animals may use timing in different contexts.

\section{CONCLUSIONS}

(1) Animals have generally been assumed to have interval-timing capacity. In some contexts, such as refuge hiding, interval timing is likely to be used in the absence of other cues. 
However, there is ambiguity in the extent to which timing is used in other contexts such as foraging.

(2) The potential adaptive value of time sense does not automatically imply that animals are directly tracking time intervals in everyday tasks even if they have the capacity to do so in laboratory studies. Instead, animals can either use a non-cognitive timing mechanism such as the behavioural theory of timing, an internal physiological cue such as oxygen depletion or an external non-temporal cue such as stride counting. These alternative strategies are likely to be context dependent, and direct evidence for their use in natural conditions is understandably scarce due to the difficulty of controlling for extraneous cues other than time in natural situations.

(3) Consequently, it is difficult to generalise or speculate on the relative importance of interval-timing versus non-temporal strategies that may be used across different species, tasks, or even variants of similar tasks. It is therefore vital to design behavioural experiments using a framework that considers the biology of specific animals.

\section{ACKNOWLEDGEMENTS}

L.N. was supported by a University of Melbourne Graduate Research Scholarship and D.S.F. was supported by the Australian Research Council (FT180100216) and the University of Melbourne. A.G.D. was supported by the Australian Research Council (DP160100161). We also thank Melissa Lam for her help in creating our figures.

This article is protected by copyright. All rights reserved. 


\section{REFERENCES}

AdDyman, C., French, R.M. \& ThOMAS, E. (2016). Computational models of interval timing. Current Opinion in Behavioral Sciences 8, 140-146.

Aharon, G., SAdot, M. \& Yovel, Y. (2017). Bats use path integration rather than acoustic flow to assess flight distance along flyways. Current Biology 27, 3650-3657.

BACON, I.E., Hurly, T.A. \& HeAly, S. (2010). Both the past and the present affect risksensitive decisions of foraging rufous hummingbirds. Behavioral Ecology 21, 626-632.

Baker, C.A., Kohashi, T., Lyons-Warren, A.M., Ma, X. \& Carlson, B.A. (2013). Multiplexed temporal coding of electric communication signals in mormyrid fishes. Journal of Experimental Biology 216, 2365-2379.

Balaban-Feld, J., Mitchell, W.A., Kotler, B.P., ViJayan, S., Tov Elem, L.T., RosenZWEIG, M.L. \& ABRAmsky, Z. (2019). Individual willingness to leave a safe refuge and the trade-off between food and safety: a test with social fish. Proceedings of the Royal Society B: Biological Sciences 286, 20190826.

Balsam, P.D., Drew, M.R. \& Gallistel, C.R. (2010). Time and associative learning. Comparative Cognition \& Behavior Reviews 5, 1-22.

BALSAM, P.D. \& GALLISTEL, C.R. (2009). Temporal maps and informativeness in associative learning. Trends in Neurosciences 32, 73-78.

BATESON, M. (2003). Interval timing and optimal foraging. In Functional and Neural Mechanisms of Interval Timing (ed WARREN H. MECK), pp. 113-141. CRC Press, Boca Raton, FL. 
BAtesOn, M. \& KACELNIK, A. (1995). Preferences for fixed and variable food sources: variability in amount and delay. Journal of the Experimental Analysis of Behavior 63, 313-329.

Benítez, M.E., Le RouX, A., Fischer, J., Beehner, J.C. \& Bergman, T.J. (2016). Acoustic and temporal variation in gelada (Theropithecus gelada) loud calls advertise male quality. International Journal of Primatology 37, 568-585.

BIEBACH, H., GoRDiJn, M. \& KREBS, J.R. (1989). Time-and-place learning by garden warblers, Sylvia borin. Animal Behaviour 37, 353-360.

BLOCK, R.A., HANCOCK, P.A. \& ZAKAY, D. (2010). How cognitive load affects duration judgments: a meta-analytic review. Acta Psychologica 134, 330-343.

Blumstein, D.T. \& Pelletier, D. (2005). Yellow-bellied marmot hiding time is sensitive to variation in costs. Canadian Journal of Zoology 83, 363-367.

Bogacz, R., Hu, P.T., Holmes, P.J. \& Cohen, J.D. (2010). Do humans produce the speedaccuracy trade-off that maximizes reward rate? Quarterly Journal of Experimental Psychology 63, 863-891.

BoIsverT, M.J. \& SHERRY, D.F. (2006). Interval timing by an invertebrate, the bumble bee Bombus impatiens. Current Biology 16, 1636-1640.

Boisvert, M.J., VeAL, A.J. \& SHERRY, D.F. (2007). Floral reward production is timed by an insect pollinator. Proceedings of the Royal Society B: Biological Sciences 274, 18311837.

BRodBeck, D.R., HAMPton, R.R. \& CHENG, K. (1998). Timing behaviour of black-capped chickadees (Parus atricapillus). Behavioural Processes 44, 183-195.

This article is protected by copyright. All rights reserved. 
Brown, S.W. (2008). Time and attention: review of the literature. In Psychology of time (ed S. GRONDIN), pp. 111-138. Emerald, Bingley.

BROWN, S.W. \& WeST, A.N. (1990). Multiple timing and the allocation of attention. Acta Psychologica 75, 103-121.

BRUnNeR, D., KACELNIK, A. \& GiBBON, J. (1992). Optimal foraging and timing processes in the starling, Sturnus vulgaris: effect of inter-capture interval. Animal Behaviour 44, 597-613.

BuHUSI, C. V. \& MECK, W.H. (2002). Differential effects of methamphetamine and haloperidol on the control of an internal clock. Behavioral Neuroscience 116, 291-297.

Buonomano, D. V. \& LAJE, R. (2011). Population clocks: motor timing with neural dynamics. Space, Time and Number in the Brain 14, 71-85.

Caraco, T., Martindale, S. \& WhitTAM, T.S. (1980). An empirical demonstration of risksensitive foraging preferences. Animal Behaviour 28, 820-830.

CARLSON, B.A. (2009). Temporal-pattern recognition by single neurons in a sensory pathway devoted to social communication behavior. Journal of Neuroscience 29, 9417-9428.

CARLSON, B.A. \& HoPKINS, C.D. (2004). Stereotyped temporal patterns in electrical communication. Animal Behaviour 68, 867-878.

CARR, J.A.R. \& WILKIE, D.M. (1997). Rats use an ordinal timer in a daily time-place learning task. Journal of Experimental Psychology: Animal Behavior Processes 23, 232.

Castellanos, M.C., Wilson, P. \& ThOMson, J.D. (2002). Dynamic nectar replenishment in flowers of penstemon (Scrophulariaceae). American Journal of Botany 89, 111-118.

CHARNOv, E.L. (1976). Optimal foraging, the marginal value theorem. Theoretical 
Population Biology 9, 129-136.

Chavez-Solis, C.E. \& AlCARAZ, G. (2015). Hiding time of the hermit crab Calcinus californiensis: observations from different shell types. Canadian Journal of Zoology 93, $559-565$.

ChittKa, L., Dyer, A.G., Bock, F. \& Dornhaus, A. (2003). Bees trade off foraging speed for accuracy. Nature 424, 388.

CHITTKA, L., SKORUPSKI, P. \& RAINE, N.E. (2009). Speed-accuracy tradeoffs in animal decision making. Trends in Ecology and Evolution 24, 400-407.

ChitTKa, L., Williams, N.M., RAsmussen, H. \& ThOMSON, J.D. (1999). Navigation without vision: bumblebee orientation in complete darkness. Proceedings of the Royal Society B: Biological Sciences 266, 45-50.

CHURCH, R.M., GETTY, D.J. \& LERNER, N.D. (1976). Duration discrimination by rats. Journal of Experimental Psychology: Animal Behavior Processes 2, 303-312.

Church, R.M. \& GiBBon, J. (1982). Temporal generalization. Journal of Experimental Psychology: Animal Behavior Processes 8, 165-186. American Psychological Association.

CLAYTON, N.S. \& DiCKINSON, A. (1998). Episodic-like memory during cache recovery by scrub jays. Nature 395, 272-274.

Clayton, N.S. \& DiCKinson, A. (1999). Scrub jays (Aphelocoma coerulescens) remember the relative time of caching as well as the location and content of their caches. Journal of Comparative Psychology 113, 403.

CoOK, R.G. \& Rosen, H.A. (2010). Temporal control of internal states in pigeons. 
Psychonomic Bulletin and Review 17, 915-922.

COOPER, W.E., HAWLENA, D. \& PÉREZ-MELladO, V. (2010). Influence of risk on hiding time by balearic lizards (Podarcis lilfordi): predator approach speed, directness, persistence, and proximity. Herpetologica 66, 131-141.

Copara, M.S., Hassan, A.S., Kyle, C.T., LibBy, L.A., RAnganath, C. \& Ekstrom, A.D. (2014). Complementary roles of human hippocampal subregions during retrieval of spatiotemporal context. Journal of Neuroscience 34, 6834-6842.

CRAFT, B.B. (2016). Risk-sensitive foraging: changes in choice due to reward quality and delay. Animal Behaviour 111, 41-47.

CRAIG, D.P.A. \& ABRAMSON, C.I. (2015). A need for individual data analyses for assessments of temporal control: invertebrate fixed interval performance. International Journal of Comparative Psychology 28, 1-39.

Craig, D.P.A., VARnON, C.A., Pollock, K.L. \& ABramson, C.I. (2015). An assessment of horse (Equus ferus caballus) responding on fixed interval schedules of reinforcement: an individual analysis. Behavioural Processes 120, 1-13.

Craig, D.P.A., VARnon, C.A., Sokolowski, M.B.C., Wells, H. \& Abramson, C.I. (2014). An assessment of fixed interval timing in free-flying honey bees (Apis mellifera ligustica): an analysis of individual performance. PLOS ONE 9, e101262.

DE VERE, A.J. \& KuCZAJ, S.A. (2016). Where are we in the study of animal emotions? Wiley Interdisciplinary Reviews: Cognitive Science 7, 354-362.

Dooling, R.J. \& PRIOR, N.H. (2017). Do we hear what birds hear in birdsong? Animal Behaviour 124, 283-289. 
Drew, M.R., Zupan, B., CoOKe, A., Couvillon, P.A. \& BAlsam, P.D. (2005). Temporal control of conditioned responding in goldfish. Journal of Experimental Psychology: Animal Behavior Processes 31, 31-39.

Drugowitsch, J., Deangelis, G.C., Angelaki, D.E. \& Pouget, A. (2015). Tuning the speed-accuracy trade-off to maximize reward rate in multisensory decision-making. eLife 4, 1-11.

DunPHY-DAly, M.M., Heithaus, M.R., WiRsing, A.J., MARdON, J.S.F. \& BuRKHOLdER, D.A. (2010). Predation risk influences the diving behavior of a marine mesopredator. The Open Ecology Journal 3, 8-15.

DYER, A.G. \& ChITTKA, L. (2004). Bumblebees (Bombus terrestris) sacrifice foraging speed to solve difficult colour discrimination tasks. Journal of Comparative Physiology A 190, 759-763.

EichenBAum, H. (2017). On the integration of space, time, and memory. Neuron 95, 10071018.

Elliott, T.M., Christensen-DAlsgaARD, J. \& Kelley, D.B. (2011). Temporally selective processing of communication signals by auditory midbrain neurons. Journal of Neurophysiology 105, 1620-1632.

Esch, H.E., Zhang, S., SRinivasan, M. V. \& TAuTZ, J. (2001). Honeybee dances communicate distances measured by optic flow. Nature 411, 581-583.

FEeney, M.C., Roberts, W.A. \& SHerry, D.F. (2009). Memory for what, where, and when in the black-capped chickadee (Poecile atricapillus). Animal Cognition 12, 767-777. Ferster, C.B. \& SKInNER, B.F. (1957). Schedules of reinforcement. Appleton-Century- 
Crofts, New York.

FilipPI, P., HoEschele, M., SPIERINGS, M. \& Bowling, D.L. (2019). Temporal modulation in speech, music, and animal vocal communication: evidence of conserved function. Annals of the New York Academy of Sciences 1453, 99-113.

Fontes, R., Ribeiro, J., Gupta, D.S., MAchado, D., LOPES-JÚnior, F., MAGAlHÃEs, F., Bastos, V.H., Rocha, K., Marinho, V., Lima, G., Velasques, B., Ribeiro, P., Orsini, M., PessoA, B., Araujo Leite, M.A., ET AL. (2016). Time perception mechanisms at central nervous system. Neurology International 8, 5939.

ForSMAN, A. \& HAGMAN, M. (2006). Calling is an honest indicator of paternal genetic quality in poison frogs. Evolution 60, 2148-2157.

Gable, P.A. \& Poole, B.D. (2012). Time flies when you're having approach-motivated fun: effects of motivational intensity on time perception. Psychological Science 23, 879-886.

Galeotti, P., SAino, N., SACChI, R. \& MølleR, A.P. (1997). Song correlates with social context, testosterone and body condition in male barn swallows. Animal Behaviour 53, $687-700$.

GARCÍA-GALLARDO, D. \& CARPIO, C. (2016). Effects of variable sequences of food availability on interval time-place learning by pigeons. Behavioural Processes 130, 5364.

GiBBon, J. (1977). Scalar expectancy theory and Weber’s law in animal timing. Psychological review 84, 279.

GIURFA, M. (2007). Behavioral and neural analysis of associative learning in the honeybee: a taste from the magic well. Journal of Comparative Physiology A 193, 801-824. 
Goel, A. \& Buonomano, D. V. (2014). Timing as an intrinsic property of neural networks: evidence from in vivo and in vitro experiments. Philosophical Transactions of the Royal Society B: Biological Sciences 369, 20120460.

GREEN, R.F. (1984). Stopping rules for optimal foragers. The American Naturalist 123, 3043.

GRONDin, S. (2001). From physical time to the first and second moments of psychological time. Psychological Bulletin 127, 22-44.

GRONDIN, S. (2010). Timing and time perception: a review of recent behavioral and neuroscience findings and theoretical directions. Attention, Perception, \& Psychophysics 72, 561-582.

GrossmanN, K.E. (1973). Continuous, fixed-ratio, and fixed-interval reinforcement in honey bees. Journal of the experimental analysis of behavior 20, 105-109.

HARDIN, P.E. (2005). The circadian timekeeping system of drosophila. Current Biology 15, $714-722$.

HAzen, E.L., Friedlaender, A.S. \& Goldbogen, J.A. (2015). Blue whales (Balaenoptera musculus) optimize foraging efficiency by balancing oxygen use and energy gain as a function of prey density. Science Advances 1, e1500469.

HEDRICK, A. V. (2000). Crickets with extravagant mating songs compensate for predation risk with extra caution. Proceedings of the Royal Society B: Biological Sciences 267, $671-675$.

HEFTY, K.L. \& STEWART, K.M. (2019). Flexible resource use strategies of a central-place forager experiencing dynamic risk and opportunity. Movement Ecology 7, 23.

This article is protected by copyright. All rights reserved. 
HeINRICH, T., DeHnhardT, G. \& HANKE, F.D. (2016). Harbour seals (Phoca vitulina) are able to time precisely. Animal Cognition 19, 1133-1142.

HEITZ, R.P. (2014). The speed-accuracy tradeoff: history, physiology, methodology, and behavior. Frontiers in Neuroscience 8, 1-19.

HEITZ, R.P. \& SCHALL, J.D. (2012). Neural mechanisms of speed-accuracy tradeoff. Neuron 76, 616-628.

Henderson, J., Hurly, T.A., Bateson, M. \& HeAly, S.D. (2006). Timing in free-living rufous hummingbirds, Selasphorus rufus. Current Biology 16, 512-515.

HERAN, H. \& WANKE, L. (1952). Beobachtungen über die entfernungsmeldung der sammelbienen. Zeitschrift für vergleichende Physiologie 34, 383-393.

HigA, J.J. \& SimM, L.A. (2004). Interval timing in Siamese fighting fish (Betta splendens). Behavioural Processes 67, 501-509.

Houston, A.I., McNAmARA, J.M. \& HutChinson, J.M.C. (1993). General results concerning the trade-off between gaining energy and avoiding predation. Philosophical Transactions of the Royal Society B: Biological Sciences 341, 375-397.

HUGIE, D.M. (2003). The waiting game: a 'battle of waits’ between predator and prey. Behavioral Ecology 14, 807-817.

INGS, T.C. \& CHITTKA, L. (2008). Speed-accuracy tradeoffs and false alarms in bee responses to cryptic predators. Current Biology 18, 1520-1524.

JenniOns, M.D., BACKWELl, P.R.Y., Murai, M. \& Christy, J.H. (2003). Hiding behaviour in fiddler crabs: how long should prey hide in response to a potential predator? Animal Behaviour 66, 251-257.

This article is protected by copyright. All rights reserved. 
JiN, D.Z., FUJII, N. \& GRAYBIEL, A.M. (2009). Neural representation of time in cortico-basal ganglia circuits. Proceedings of the National Academy of Sciences 106, 19156-19161.

Jones, M.R. \& Boltz, M. (1989). Dynamic attending and responses to time. Psychological review 96, 459-491.

KACELNIK, A. \& BRUnNER, D. (2002). Timing and foraging: Gibbon's scalar expectancy theory and optimal patch exploitation. Learning and Motivation 33, 177-195.

KACELniK, A., BRunNeR, D. \& GiBBOn, J. (1990). Timing mechanisms in optimal foraging: some applications of scalar expectancy theory. In Behavioural Mechanisms of Food Selection pp. 61-82.

KACELNIK, A. \& El Mouden, C. (2013). Triumphs and trials of the risk paradigm. Animal Behaviour 86, 1117-1129.

KARMARKAR, U.R. \& BUONOMANO, D. V. (2007). Timing in the absence of clocks: encoding time in neural network states. Neuron 53, 427-438.

KinSLINGER, R.L. \& KLIMLEY, A.P. (2002). Species identity and the temporal characteristics of fish acoustic signals. Journal of Comparative Psychology 116, 210-214.

Killeen, P.R. \& Fetterman, J.G. (1988). A behavioral theory of timing. Psychological Review 95, 274-295.

KIM, J., GHIM, J.W., LEE, J.H. \& JunG, M.W. (2013). Neural correlates of interval timing in rodent prefrontal cortex. Journal of Neuroscience 33, 13834-13847.

KLeinman, M.R., SoHn, H. \& LEe, D. (2016). A two-stage model of concurrent interval timing in monkeys. Journal of Neurophysiology 116, 1068-1081.

KostaraKos, K. \& HedWig, B. (2014). Pattern recognition in field crickets: concepts and 
neural evidence. Journal of Comparative Physiology A 201, 73-85.

LAKE, J.I., LABAR, K.S. \& MECK, W.H. (2016). Emotional modulation of interval timing and time perception. Neuroscience and Biobehavioral Reviews 64, 403-420.

LANGER, J., WAPNER, S. \& WERNER, H. (1961). The effect of danger upon the experience of time. The American journal of psychology 74, 94-97.

LeJEune, H. \& RiCHELLE, M. (1982). Fixed interval performance in turtle doves: a comparison with pigeons and rats. Behaviour Analysis Letters 2, 87-95.

LEWIS, S.M. \& CRATSLEY, C.K. (2008). Flash signal evolution, mate choice, and predation in fireflies. Annual Review of Entomology 53, 293-321.

Liesenjohann, T., Liesenjohann, M., Trebaticka, L., Sundell, J., HaAPAKOSKi, M., YLÖNEN, H. \& ECCARD, J.A. (2015). State-dependent foraging: lactating voles adjust their foraging behavior according to the presence of a potential nest predator and season. Behavioral Ecology and Sociobiology 69, 747-754.

Lihoreau, M., RAine, N.E., ReynOldS, A.M., Stelzer, R.J., LiM, K.S., SMith, A.D., OsBORNE, J.L. \& CHITTKA, L. (2013). Unravelling the mechanisms of trapline foraging in bees. Communicative \& Integrative Biology 6, e22701.

LIMA, S.L. (1985). Maximizing feeding efficiency and minimizing time exposed to predators : a trade-off in the black-capped chickadee. Oecologia 66, 60-67.

LIMA, S.L. \& DiLL, L.M. (1990). Behavioral decisions made under the risk of predation: a review and prospectus. Canadian Journal of Zoology 68, 619-640.

LuO, E.Y., OGILVIE, J.E. \& THOMPSON, J.D. (2014). Stimulation of flower nectar replenishment by removal: a survey of eleven animal-pollinated plant species. Journal of 
Pollination Ecology 12, 52-62.

MaCDonALD, C.J. \& MECK, W.H. (2003). Time flies and may also sing: cortico-striatal mechanisms of interval timing and birdsong. In Functional and Neural Mechanisms of Interval Timing (ed W.H. MECH), pp. 401-426. CRC Press, Boca Raton.

MACHADO, A. (1997). Learning the temporal dynamics of behavior. Psychological Review 104, 241-265.

MACInNIS, M.L.M. \& GUILHARDI, P. (2006). Basic temporal discrimination procedures. In Tasks and techniques: a sampling of the methodologies for the investigation of animal learning, behavior, and cognition (ed M. J. ANDERSON), pp. 233-244. Nova Science Publishers, Hauppauge.

MANDAL, S. (2018). How do animals find their way back home? a brief overview of homing behavior with special reference to social hymenoptera. Insectes Sociaux 65, 521-536.

Marshall, H.H., Carter, A.J., Ashford, A., Rowcliffe, J.M. \& Cowlishaw, G. (2013). How do foragers decide when to leave a patch? A test of alternative models under natural and experimental conditions. Journal of Animal Ecology 82, 894-902.

MARTín, J. \& LÓPEZ, P. (2015). Hiding time in refuge. In Escaping from predators: an integrative view of escape decisions (ed D.T. BLUMSTEIN), pp. 227-262. Cambridge University Press, Cambridge.

Martin-Ordas, G., Haun, D., Colmenares, F. \& Call, J. (2010). Keeping track of time: evidence for episodic-like memory in great apes. Animal Cognition 13, 331-340.

MATELL, M.S. \& MECK, W.H. (2000). Neuropsychological mechanisms of interval timing behavior. BioEssays 22, 94-103.

This article is protected by copyright. All rights reserved. 
MATELL, M.S. \& MECK, W.H. (2004). Cortico-striatal circuits and interval timing: coincidence detection of oscillatory processes. Cognitive brain research 21, 139-170.

Matell, M.S., MecK, W.H. \& NiCOlELIS, M.A.L. (2003). Interval timing and the encoding of signal duration by ensembles of cortical and striatal neurons. Behavioral Neuroscience 117, 760-773.

McMillan, N., KIRK, C.R. \& Roberts, W.A. (2014). Pigeon (Columba livia) and rat (Rattus norvegicus) performance in the midsession reversal procedure depends upon cue dimensionality. Journal of Comparative Psychology 128, 357-366.

McMillan, N., Spetch, M.L., Sturdy, C.B. \& RoberTs, W.A. (2017). It’s all a matter of time: interval timing and competition for stimulus control. Comparative Cognition \& Behavior Reviews 12, 83-103.

Møller, A. (1991). Parasite load reduces song output in a passerine bird. Animal Behaviour 41, 723-730.

Mooney, R. (2009). Neural mechanisms for learned birdsong. Learning and Memory 16, 655-669.

Motanis, H., Seay, M.J. \& Buonomano, D. V. (2018). Short-term synaptic plasticity as a mechanism for sensory timing. Trends in Neurosciences 41, 701-711.

MourA, C. DE A. \& LuCHIARI, A.C. (2016). Time-place learning in the zebrafish (Danio rerio). Behavioural Processes 128, 64-69.

Mulder, C., Gerkema, M.P. \& VAn DeR ZeE, E.A. (2013). Circadian clocks and memory: time-place learning. Frontiers in Molecular Neuroscience 6, 1-10.

NonACs, P. (2001). State dependent behavior and the marginal value theorem. Behavioral 
Ecology 12, 71-83.

NotTeBOHM, F. (2005). The neural basis of birdsong. PLoS Biology 3, 0759-0761.

Ohyama, T., GibBon, J., Deich, J.D. \& BALsam, E.D. (1999). Temporal control during maintenance and extinction of conditioned keypecking in ring doves. Animal Learning \& Behavior 27, 89-98.

PACHELLA, R.G. \& FISHER, D.F. (1969). Effect of stimulus degradation and similarity on the trade-off between speed and accuracy in absolute judgments. Journal of Experimental Psychology 81, 7-9.

Parent, J.P., Brodeur, J. \& Boivin, G. (2016). Use of time in a decision-making process by a parasitoid. Ecological Entomology 41, 727-732.

PATON, J.J. \& BuONOMANO, D. V. (2018). The neural basis of timing: distributed mechanisms for diverse functions. Neuron 98, 687-705.

PAUL, E.S. \& MENDL, M.T. (2018). Animal emotion: descriptive and prescriptive definitions and their implications for a comparative perspective. Applied Animal Behaviour Science 205, 202-209.

PaulK, A.C., Phillips-Portillo, J., Dacks, A.M., Fellous, J.M. \& GronenBerg, W. (2008). The processing of color, motion, and stimulus timing are anatomically segregated in the bumblebee brain. Journal of Neuroscience 28, 6319-6332.

Penney, T.B., GibBon, J. \& MeCK, W.H. (2008). Categorical scaling of duration bisection in pigeons (Columba livia), Mice (Mus musculus), and humans (Homo sapiens). Psychological Science 19, 1103-1109.

PFLUMM, W. (1986). Rate of supply of sugar solution and behaviour of collector wasps 
(Paravespula germanica). Ethology 72, 15-21.

Pizzo, M.J. \& CRYstal, J.D. (2004). Time-place learning in the eight-arm radial maze. Learning and Behavior 32, 240-255.

POLlACK, G. (2000). Who, what, where? Recognition and localization of acoustic signals by insects. Current Opinion in Neurobiology, 763-767.

Ponganis, P.J., Meir, J.U. \& Williams, C.L. (2010). Oxygen store depletion and the aerobic dive limit in emperor penguins. Aquatic Biology 8, 237-245.

RAMMSAYER, T.H. (1999). Neuropharmacological evidence for different timing mechanisms in humans. The Quarterly Journal of Experimental Psychology Section B 52, 273-286.

RAMMSAYER, T.H., BORTER, N. \& TROCHE, S.J. (2015). Visual-auditory differences in duration discrimination of intervals in the subsecond and second range. Frontiers in Psychology 6, 1-7.

Ravignani, A., Dalla Bella, S., Falk, S., Kello, C.T., Noriega, F. \& Kotz, S.A. (2019). Rhythm in speech and animal vocalizations: a cross-species perspective. Annals of the New York Academy of Sciences 1453, 79-98.

Rayburn-Reeves, R.M., Molet, M. \& Zentall, T.R. (2011). Simultaneous discrimination reversal learning in pigeons and humans: anticipatory and perseverative errors. Learning and Behavior 39, 125-137.

REANEY, L.T. (2007). Foraging and mating opportunities influence refuge use in the fiddler crab, Uca mjoebergi. Animal Behaviour 73, 711-716.

RhoAdes, E. \& Blumstein, D.T. (2007). Predicted fitness consequences of threat-sensitive hiding behavior. Behavioral Ecology 18, 937-943. 
Richardson, C., Joly, P., LÉnA, J.P., Plénet, S. \& Lengagne, T. (2010). The challenge of finding a high-quality male: a treefrog solution based on female assessment of male calls. Behaviour 147, 1737-1752.

Rinberg, D., Koulakov, A. \& Gelperin, A. (2006). Speed-accuracy tradeoff in olfaction. Neuron 51, 351-358.

ROBERTS, W.A. (2006). Evidence that pigeons represent both time and number on a logarithmic scale. Behavioural Processes 72, 207-214.

RONACHER, B. \& STUMPNER, A. (1988). Filtering of behaviourally relevant temporal parameters of a grasshopper's song by an auditory interneuron. Journal of Comparative Physiology A 163, 517-523.

Sackett, A.M., Meyvis, T., Nelson, L.D., Converse, B.A. \& SacketT, A.L. (2010). You're having fun when time flies: the hedonic consequences of subjective time progression. Psychological Science 21, 111-117.

Saino, N., Galeotti, P., SACChi, R. \& Møller, A.P. (1997). Song and immunological condition in male barn swallows (Hirundo rustica). Behavioral Ecology 8, 364-371.

SAKSIDA, L.M. \& WILKIE, D.M. (1994). Time-of-day discrimination by pigeons. Animal Learning \& Behavior 22, 143-154.

SALWICZEK, L.H. \& BshaRY, R. (2011). Cleaner wrasses keep track of the 'when' and 'what' in a foraging task. Ethology 117, 939-948.

SARPESHKAR, R. (2014). Analog synthetic biology. Philosophical Transactions of the Royal Society A: Mathematical, Physical and Engineering Sciences 372, 20130110.

Scheuber, H., JACOT, A. \& BRinKHOF, M.W.G. (2003). Condition dependence of a 
multicomponent sexual signal in the field cricket Gryllus campestris. Animal Behaviour 65, 721-727.

SCHILMAN, P.E. \& RocEs, F. (2003). Assessment of nectar flow rate and memory for patch quality in the ant Camponotus rufipes. Animal Behaviour 66, 687-693.

SCHMIDT, J.M. \& SMITH, J.J.B. (1987). Short interval time measurement by a parasitoid wasp. Science 237, 903-905.

Schroeder, T.B.H., Houghtaling, J., Wilts, B.D. \& MAYER, M. (2018). It’s not a bug, it’s a feature: functional materials in insects. Advanced Materials 30, 1705322.

Seeley, T.D., MikheyeV, A.S. \& Pagano, G.J. (2000). Dancing bees tune both duration and rate of waggle-run production in relation to nectar-source profitability. Journal of Comparative Physiology A 186, 813-819.

SIH, A. (1992). Prey uncertainty and the balancing of antipredator and feeding needs. The American Naturalist 139, 1052-1069.

StePhens, D.W. \& KreBs, J.R. (1986). Foraging theory. Princeton University Press, Princeton.

Tello-Ramos, M.C., Hurly, T.A. \& Healy, S.D. (2015). Traplining in hummingbirds: flying short-distance sequences among several locations. Behavioral Ecology 26, 812819.

THALER, J.S., MCARTA, S.H. \& KAPLAN, I. (2012). Compensatory mechanisms for ameliorating the fundamental trade-off between predator avoidance and foraging. Proceedings of the National Academy of Sciences 109, 12075-12080.

Thomson, J.D., McKenna, M.A. \& CRuZAn, M.B. (1989). Temporal patterns of nectar and 
pollen production in Aralia hispida: implications for reproductive success. Ecology 70, 1061-1068.

ThORPE, C.M. \& WiLkiE, D.M. (2006a). Properties of time-place learning. In Comparative Cognition: Experimental Explorations of Animal Intelligence (eds E.A. WASSERMAN \& T.R. ZENTALL), pp. 229-245. Oxford University Press, Oxford.

THORPE, C.M. \& WiLKIE, D.M. (2006b). Rats’ performance on an interval time-place task: increasing sequence complexity. Learning and Behavior 34, 248-254.

TIPPLES, J. (2008). Negative emotionality influences the effects of emotion on time perception. Emotion 8, 127-131.

ToBias, M.L., Evans, B.J. \& KeLley, D.B. (2011). Evolution of advertisement calls in african clawed frogs. Behaviour 148, 519-549.

TOELCH, U. \& WiNTER, Y. (2013). Interval timing behavior in Pallas’s long-tongued bat (Glossophaga soricina). Journal of Comparative Psychology 127, 445-452.

ToH, K.L. (2008). Basic science review on circadian rhythm biology and circadian sleep disorders. Annals of the Academy of Medicine Singapore 37, 662-668.

VAN RIJN, H. (2018). Towards ecologically valid interval timing. Trends in Cognitive Sciences 22, 850-852.

Vasconcelos, M., De Carvalho, M.P. \& Machado, A. (2017). Timing in animals: from the natural environment to the laboratory, from data to models. In APA handbook of comparative psychology: Perception, learning, and cognition. (ed J. CALL), pp. 509534. American Psychological Association, Washington.

VERDOLIN, J.L. (2006). Meta-analysis of foraging and predation risk trade-offs in terrestrial 
systems. Behavioral Ecology and Sociobiology 60, 457-464.

VignAL, C. \& KeLLEY, D. (2007). Significance of temporal and spectral acoustic cues for sexual recognition in Xenopus laevis. Proceedings of the Royal Society B: Biological Sciences 274, 479-488.

VON FRISCH, K. (1967). The dance language and orientation of bees. Harvard University Press, Cambridge.

WAinSELbOIM, A.J., RoCES, F. \& FARINA, W.M. (2002). Honeybees assess changes in nectar flow within a single foraging bout. Animal Behaviour 63, 1-6.

Wallace, D.G., Hines, D.J., Pellis, S.M. \& Whishaw, I.Q. (2002). Vestibular information is required for dead reckoning in the rat. Journal of Neuroscience 22, 10009-10017.

Wallace, D.G., Wallace, P.S., Field, E. \& WhishaW, I.Q. (2006). Pharmacological manipulations of food protection behavior in rats: evidence for dopaminergic contributions to time perception during a natural behavior. Brain Research 1112, 213221.

WALLS, M.L. \& LAYNE, J.E. (2009). Direct evidence for distance measurement via flexible stride integration in the fiddler crab. Current Biology 19, 25-29.

WANG, M.Y., CHITTKA, L. \& INGS, T.C. (2018). Bumblebees express consistent, but flexible, speed-accuracy tactics under different levels of predation threat. Frontiers in Psychology 9, 1-11.

WAtAnABe, Y.Y., ITO, M. \& TAKAHASHI, A. (2014). Testing optimal foraging theory in a penguin-krill system. Proceedings of the Royal Society B: Biological Sciences 281, 20132376.

This article is protected by copyright. All rights reserved. 
WeISS, D.J., GARIBALDI, B.T. \& HAUSER, M.D. (2001). The production and perception of long calls by cotton-top tamarins (Saguinus oedipus): acoustic analyses and playback experiments. Journal of Comparative Psychology 115, 258-271.

WHISHAW, I.Q. \& GORNY, B.P. (1994). Food wrenching and dodging: eating time estimates influence dodge probability and amplitude. Aggressive Behavior 20, 35-47.

WiLKIE, D.M., SAKSIDA, L.M., SAMSON, P. \& LEE, A. (1994). Properties of time-place learning by pigeons, Columba livia. Behavioural Processes 31, 39-56.

WitTMAnN, M. \& VAN WASSENHOVE, V. (2009). The experience of time: neural mechanisms and the interplay of emotion, cognition and embodiment. Philosophical Transactions of the Royal Society B: Biological Sciences 364, 1809-1813.

Wohlgemuth, S., Ronacher, B. \& Wehner, R. (2001). Ant odometry in the third dimension. Nature 411, 795-798.

WoLf, H. (2011). Odometry and insect navigation. Journal of Experimental Biology 214, 1629-1641.

Wolf, H., WitTlinger, M. \& PfefFer, S.E. (2018). Two distance memories in desert antsmodes of interaction. PLOS ONE 13, 1-19.

Wollerman, L. \& Wiley, R.H. (2002). Possibilities for error during communication by neotropical frogs in a complex acoustic environment. Behavioral Ecology and Sociobiology 52, 465-473.

Xu, M., ZHANG, S.Y., DAN, Y. \& PoO, M.M. (2014). Representation of interval timing by temporally scalable firing patterns in rat prefrontal cortex. Proceedings of the National Academy of Sciences of the United States of America 111, 480-485.

This article is protected by copyright. All rights reserved. 
YAMADA, Y. \& KAWABE, T. (2011). Emotion colors time perception unconsciously. Consciousness and Cognition 20, 1835-1841.

ZEILER, M.D. (1991). Ecological influences on timing. Journal of Experimental Psychology: Animal Behavior Processes 17, 13-25.

ZENTALL, T.R. (2020). The midsession reversal task: a theoretical analysis. Learning and Behavior 48, 195-207.

ZINKIVSKAY, A., NAZIR, F. \& SMULDERS, T. V. (2009). What-where-when memory in magpies (Pica pica). Animal Cognition 12, 119-125.

ZuK, M., REBAR, D. \& SCOTT, S.P. (2008). Courtship song is more variable than calling song in the field cricket Teleogryllus oceanicus. Animal Behaviour 76, 1065-1071.

This article is protected by copyright. All rights reserved. 
Table 1. Ecological contexts and tasks in which interval timing may be used by animals.

\begin{tabular}{|c|c|c|c|}
\hline Ecological context & Task & Example & Reference \\
\hline \multirow[t]{5}{*}{ Foraging } & $\begin{array}{l}\text { Calculating resource } \\
\text { acquisition over time }\end{array}$ & $\begin{array}{l}\text { Adélie penguins assess short-term and } \\
\text { long-term foraging patch quality, and } \\
\text { this influences the time they spend at } \\
\text { patches }\end{array}$ & Watanabe et al. (2014) \\
\hline & $\begin{array}{l}\text { Tracking foraging or } \\
\text { search duration }\end{array}$ & $\begin{array}{l}\text { Rats measure the delay to reward and use } \\
\text { this information to develop preferences } \\
\text { for risk-prone or risk-averse options }\end{array}$ & Craft (2016) \\
\hline & $\begin{array}{l}\text { Timing food } \\
\text { replenishment intervals }\end{array}$ & $\begin{array}{l}\text { Hummingbirds track the time schedule of } \\
\text { artificial feeders and avoid feeders that } \\
\text { were visited recently }\end{array}$ & Henderson et al. (2006) \\
\hline & $\begin{array}{l}\text { Making speed- } \\
\text { accuracy trade-offs }\end{array}$ & $\begin{array}{l}\text { Bumblebees flexibly adjust their decision } \\
\text { speed according to the predation threat } \\
\text { level }\end{array}$ & $\begin{array}{l}\text { Ings \& Chittka (2008); } \\
\text { Wang et al. (2018) }\end{array}$ \\
\hline & Time-place learning & $\begin{array}{l}\text { Pigeons can learn temporal and spatial } \\
\text { cues to determine where to find a food } \\
\text { reward at short time scales }\end{array}$ & $\begin{array}{l}\text { Wilkie et al. (1994); } \\
\text { García-Gallardo \& Carpio } \\
\text { (2016) }\end{array}$ \\
\hline \multirow[t]{2}{*}{ Communication } & $\begin{array}{l}\text { Processing individual } \\
\text { temporal elements } \\
\text { within a signal }\end{array}$ & $\begin{array}{l}\text { Honeybees communicate the distance of } \\
\text { a food source through the duration of the } \\
\text { waggle run in their dance language }\end{array}$ & $\begin{array}{l}\text { von Frisch (1967); Seeley } \\
\text { et al. (2000) }\end{array}$ \\
\hline & $\begin{array}{l}\text { Processing rhythmic } \\
\text { structures in signals }\end{array}$ & $\begin{array}{l}\text { African clawed frogs communicate their } \\
\text { sexual identity using gender-specific } \\
\text { acoustic patterns and carrier frequencies }\end{array}$ & Vignal \& Kelley (2007) \\
\hline \multirow[t]{2}{*}{ Predator avoidance } & $\begin{array}{l}\text { Timing predator } \\
\text { exposure }\end{array}$ & $\begin{array}{l}\text { Pied cormorants manage how much time } \\
\text { they spend at the surface where they are } \\
\text { most vulnerable in response to seasonal } \\
\text { predation risk }\end{array}$ & Dunphy-daly et al. (2010) \\
\hline & Timing refuge hiding & $\begin{array}{l}\text { Fiddler crabs manage the duration they } \\
\text { spend hiding in their refuges in response } \\
\text { to the proximity of predators. }\end{array}$ & Jennions et al. (2003) \\
\hline Navigation & $\begin{array}{l}\text { Calculating distance } \\
\text { travelled using a } \\
\text { temporal odometer }\end{array}$ & $\begin{array}{l}\text { Parasitoid wasps measure distance } \\
\text { travelled across a host egg by tracking } \\
\text { time instead of counting steps }\end{array}$ & $\begin{array}{l}\text { Schmidt \& Smith (1987); } \\
\text { Parent et al. (2016) }\end{array}$ \\
\hline
\end{tabular}


Figure legends

Fig. 1. Neurobiological, traditional psychophysics, and behavioural ecology evidence for interval timing is required to develop a cohesive understanding of interval timing in animals. Created with BioRender.com

Fig. 2. The fixed-interval schedule (Ferster \& Skinner, 1957) is a classic experimental paradigm used to investigate interval timing. (A) An animal must make a response such as pressing a lever within a time schedule to receive a reward or avoid punishment. If the animal learns a relatively long schedule over time (e.g. 80 s), we expect a 'scalloped' pattern (B) when measuring the number of responses made over the course of the experiment. This pattern is created by rapid responses as the time for reinforcement approaches, and then a pause after reinforcement.

Fig. 3. Example of an ecologically relevant interval-timing experiment by Boisvert et al. (2007). Bumblebees foraged from a patch with low-quality artificial flowers (LQF; light blue circles), and a single high-quality artificial flower (HQF; dark blue circle). Bees could freely access LQFs but the HQF only provided food after a fixed delay. This delay occurred at a pattern of 30s, 150s, then 30s, where each delay was experienced for 20 foraging bouts. Bumblebees waited longer before visiting the HQF when the delay was 150s compared to when the delay was 30s, showing that they use their time sense to optimise foraging efficiency even in the presence of LQFs. Bumblebees timed these food schedules in a free- 
flying context where a broad range of behaviours were possible, and where they could attend to a variety of stimuli within the enclosure.

Fig. 4. Schematic illustration demonstrating a framework for the design of ecologically informed interval-timing experiments. Blue represents suggestions when interval timing has been previously tested, while red represents suggestions when timing has not been previously tested. 


\section{Neurobiological}

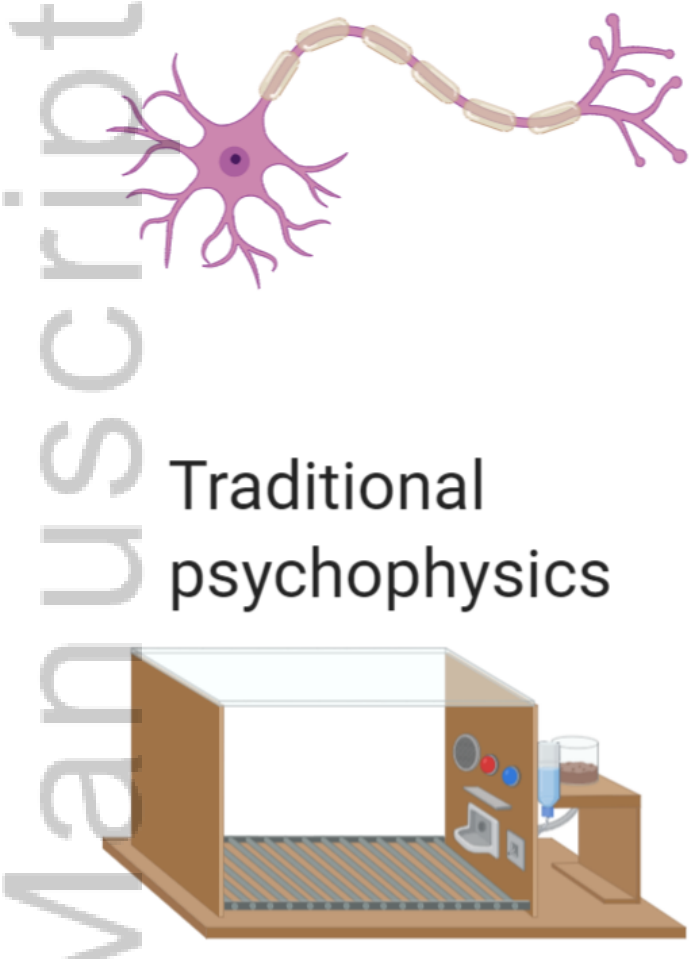

\begin{abstract}
Provides evidence for neural mechanisms or temporal properties of neurons during tasks
\end{abstract}

Provides evidence for the behavioural capacity of interval timing, and the effect of controlled parameters on performance

\section{Behavioural} ecology

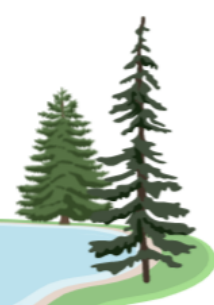

Provides evidence for the ecological relevance of interval timing under natural conditions

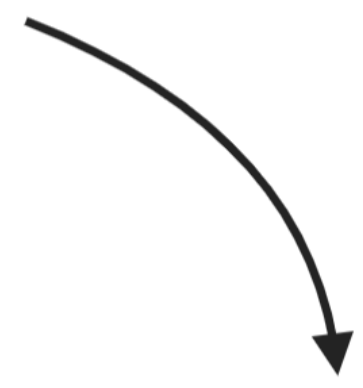

Cohesive $\longrightarrow$ understanding of interval timing

BRV_12665_Fig1.png 

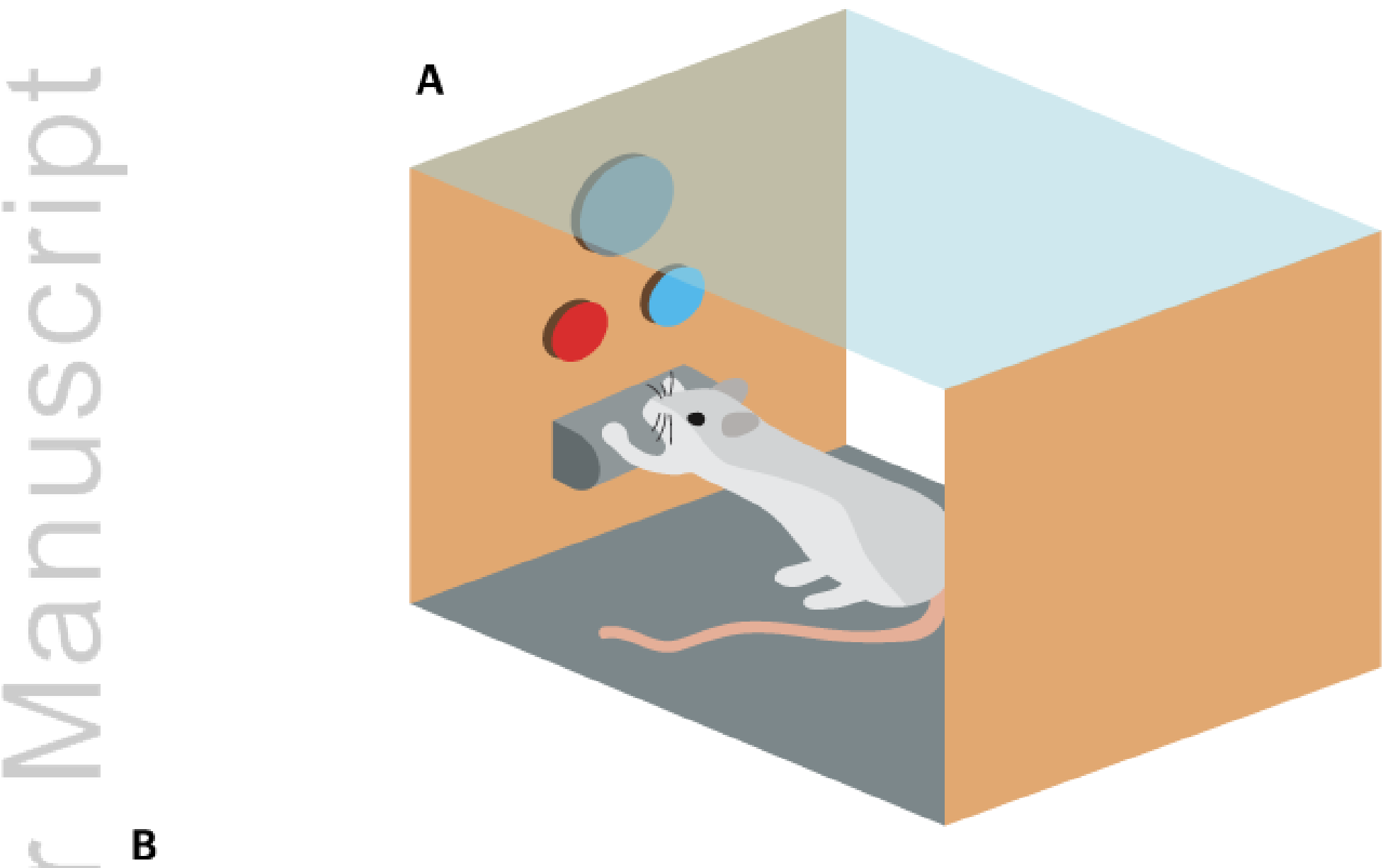

B

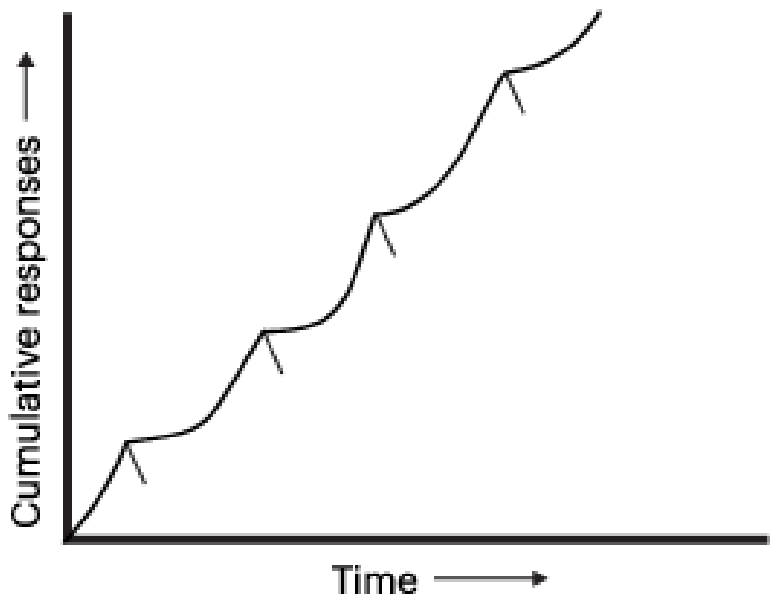

BRV_12665_Fig2.png

This article is protected by copyright. All rights reserved. 
Identify study species

e.g. honeybee

Identify the ecological context(s)

where interval timing is important

e.g. flower handling times for optimal foraging

Test interval timing in the same context

Has interval timing been previously tested in this context?

e.g. honeybees have been tested using fixed-interval schedule experiments (foraging context)
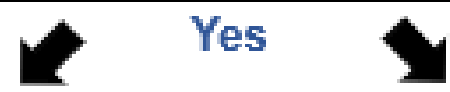

Test in the same context but manipulate ecologically relevant factors that may influence timing

e.g. do different states of stress affects interval timing?

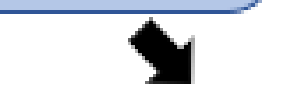

Test in the same context but using an ecologically relevant design

e.g. can free-flying bees optimise timing during foraging?
Test interval timing in a different or more relevant context

e.g. can honeybees time vibration signa/s?

No could be used to solve interval-timing tasks in this context

e.g. cues such as energy expenditure or behavioural patterns can act as a proxy for timing the duration of temporal signals

Design experiments that are relevant to the ecological context and species biology
Control for alternative cues to test if the animal is using interval timing to solve a temporal task

e.g. can honeybees learn flower handling times when alternative cues

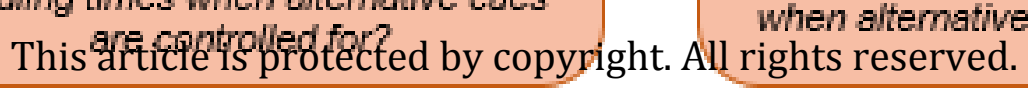

Test using an interval-timing task where attention is not controlled for

e.g. can honeybees use flower handling times to forage efficiently when alternative cues are available? 


\section{Low-quality feeders}

High-quality
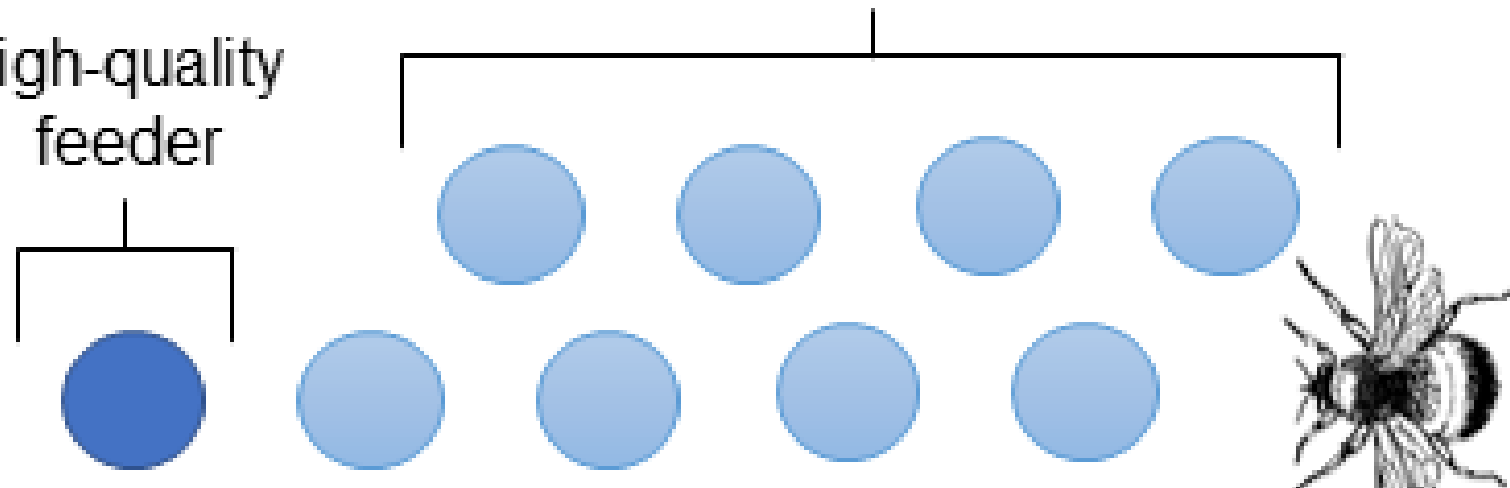

$50 \%$ sucrose available after a fixed delay during each bout
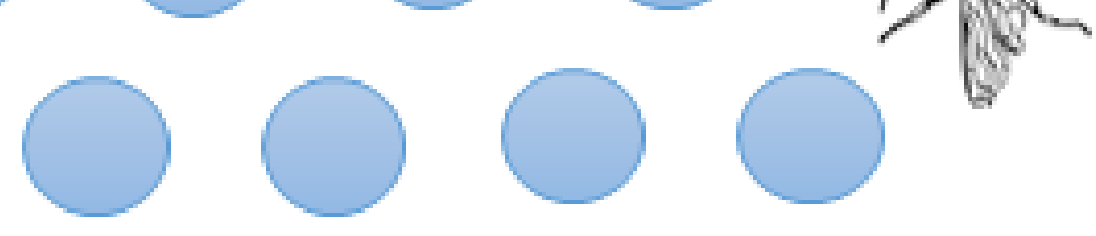

$25 \%$ sucrose available at

the start of each bout

BRV_12665_Fig. 3.png 


\section{University Library}

\section{- M M I N E R VA A gateway to Melbourne's research publications}

Minerva Access is the Institutional Repository of The University of Melbourne

Author/s:

Ng, L;Garcia, JE;Dyer, AG;Stuart-Fox, D

Title:

The ecological significance of time sense in animals

Date:

2021-04

Citation:

Ng, L., Garcia, J. E., Dyer, A. G. \& Stuart-Fox, D. (2021). The ecological significance of time sense in animals. BIOLOGICAL REVIEWS, 96 (2), pp.526-540. https://doi.org/10.1111/ brv. 12665.

Persistent Link:

http://hdl.handle.net/11343/276584 